GUEST EDITORIAL

\title{
Asthma in South African children: Reflection on new recommendations for care
}

The South African Childhood Asthma Working Group (SACAWG), a subcommittee of the Allergy Society of South Africa (ALLSA), published the first national asthma guidelines for children in 1992. ${ }^{[1]}$ Since then, the understanding of asthma and management strategies have evolved considerably. Asthma is now considered to be a spectrum of illness, reflecting different underlying inflammatory and airway processes. ${ }^{[2]}$ Over the past two decades, the importance of airway inflammation underlying asthma pathogenesis (rather than bronchoconstriction) has been recognised, with guidelines increasingly focused on effectively controlling chronic asthma symptoms, as well as preventing acute exacerbations through inhaled therapy.

These important asthma management recommendations have also been included in guidelines published by the Global Initiative for Asthma (GINA), which grew out of collaboration between the National Heart, Lung, and Blood Institute (NHLBI) and the World Health Organization (WHO). ${ }^{[3]}$

Local guidelines, based on international recommendations, and including acute exacerbation management, have filled an important role (Table 1) ${ }^{[4]}$

Asthma is the most common non-communicable disease in South Africa (SA). ${ }^{[5]}$ Unfortunately, management groups and management strategies are competing for scarce healthcare resources, which also have to satisfy the needs of many serious and common communicable conditions, including HIV, tuberculosis (TB) and pneumonia. Despite these challenges, numerous successes have been facilitated for SA children with asthma, including widespread availability of inhaled corticosteroids (ICSs), spacer devices and many programmes to educate healthcare providers, asthmatic children and their caregivers.

However, we have a long way to go in ensuring that every asthmatic child is well controlled and no longer suffers from asthma symptoms, which impact quality of life (Table 2).

Table 1. The value of local guidelines and recommendations

They are a summary of current evidence for disease management

They are written by 'experts' in the disease profile

They lead local health authority strategies for management

They have an impact on managed healthcare interventions

They provide a legal basis for adjudicating medicolegal claims

They provide a cost-effective strategy in line with local

health conditions

They summarise care for busy practitioners

Table 2. Problems in managing childhood asthma

Presentation based on symptoms v. objective testing

Under-diagnosis and diagnosis in preschool children

Device usage by age

Adherence to therapy

More common triggers, e.g. upper-respiratory tract infections

Managing comorbidities, especially allergic rhinitis

Concern for systemic effects of inhaled corticosteroids
For many years, SA guidelines and international guidelines advocated a step-wise control scheme for drug selection for asthma control. This step-wise plan did not suggest that all asthmatics must start at step 1 and then escalate therapy as necessary. Rather, it provided a schematic way to reflect that asthma is a condition with various levels of expression and, therefore, therapies should be tailored to an individual patient's level of morbidity. However, until recently, step 1 was incorporated in all guidelines. It suggested that some asthmatics may have such mild asthma that they required only intermittent short-acting beta-2 agonist (SABA) bronchodilator treatment. Many insisted that this was such an uncommon scenario that its inclusion in guidelines allowed patients to use a form of therapy that was unproven, but also well known to cause harm..$^{[-9]}$ This recommendation dates back more than 50 years, when asthma was thought to be primarily a disease of bronchoconstriction. However, it is now known that even mild or intermittent asthma is invariably associated with underlying airway inflammation. Therefore, in 2019, the GINA guidelines removed this step for adolescents and adults, recommending that an ICS always be used in conjunction with a bronchodilator. ${ }^{[10]}$ An ICS-long-acting beta-2 agonist should be used either for symptoms (intermittently for mild asthma) or daily (to control asthma symptoms and reduce exacerbations) in adolescents. Unfortunately, data in children $<12$ years of age are still lacking, but we look forward to further evidence in children and revision of guidelines. In children $6-11$ years of age, low-dose ICS or an ICS together with a SABA is recommended as the first step in the revised GINA guidelines.

Asthma control is now the buzzword in asthma circles. Asthma control means the total absence of asthma symptoms, including night-time awakening, day-time cough or wheeze, exercise-induced symptoms, and no reliever therapy. Clearly, exacerbations are completely unacceptable, as these 'lung attacks' reduce lung function, and cause irreparable harm and death. Assessing asthma control should be the goal of a follow-up visit, but unfortunately this is often not done. Many scoring systems have been made available by companies and the National Asthma Education Programme (NAEP) (including the asthma control test). ${ }^{[1]}$ Until we allow patients to share their ongoing symptoms in a safe and helpful manner, asthma continues to be a disease of significant morbidity. ${ }^{[12]}$

In addition to assessing asthma control, the most important aspect of asthma management is patient and parent education. The principles of an education plan are reflected in Table 3.

Finally, as a subgroup of ALLSA, we hope that the diseases associated with asthma and comorbid conditions are also adequately managed by healthcare practitioners. These include atopic dermatitis and allergic rhinitis. There are SA recommendations for the management of all allergic conditions, ${ }^{[14-16]}$ but these need to be used alongside the recommendations, as asthma often co-exists with allergic conditions.

We have lived through two waves of COVID-19 in SA, with a huge impact on our population, including children. Fortunately, the evidence suggests that children with stable asthma controlled on ICS therapy do not develop more severe COVID-19 symptoms than those without asthma. ${ }^{[17]}$ However, viral infections are well known to trigger 
Table 3. Elements of a successful asthma education plan ${ }^{[13]}$

Explain the inflammatory nature of the disease and need for regular control (adherence)

Describe and regularly check delivery methods for medication, especially nasal therapy and inhalers (technique)

Use of therapies for comorbid conditions

Treat flares and exacerbations

Monitor control of the disease

Regular check-ups

Avoid known allergens (including hidden sources) and irritants

Avoid unnecessary and unsafe therapies and practices

Provide written material or reputable web addresses for such access

asthma exacerbations. This is yet another reason why good asthma control is crucial in every asthmatic at this time.

This issue of CME contains two articles reviewing aspects of paediatric asthma: a summary of new recommendations for

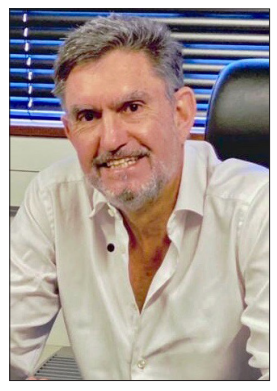
asthma diagnosis and management, ${ }^{[18]}$ and prevention of viral induced asthma exacerbations. ${ }^{[19]}$ We trust that this update on recommendations for children with asthma will promote care for many children.

\section{R J Green}

Department of Paediatrics and Child Health, Faculty of Health Sciences, University of

Pretoria, South Africa

robin.green@up.ac.za

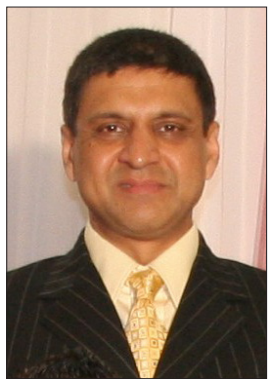

A I Manjra

Allergy and Asthma Centre, Westville

Hospital, Durban, South Africa

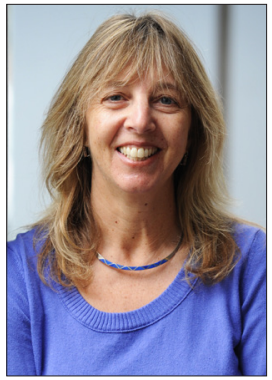

H J Zar

MRC Unit on Child and Adolescent Health, Department of Paediatrics and Child Health, Faculty of Health Sciences, University of Cape Town, South Africa
1. South African Childhood Asthma Working Group. Management of childhood and adolescent asthma - 1991 consensus. S Afr Med J 1992:81(1):38-40.

2. Pavord ID, Beasley R, Agusti A, et al. After asthma: Redefining airways diseases. Lancet 2018;391(10118):350-400. https://doi.org/10.1016/S0140-6736(17)30879-6

3. Global Strategy for Asthma Management and Prevention. NHLBI/WHO Workshop Report, US Department of Health and Human Services, Public Health Service, National Institutes of Health, National Heart, Lung and Blood Institute. NIH Publication No. 96-3659B. 1995. https://ginasthma. org/wp-content/uploads/2019/01/2004-GINA.pdf (accessed 25 March 2021).

4. South African Childhood Asthma Working Group. Management of acute asthmatic attacks in children. S Afr Med J 1993;83(4):286-289.

5. Ait-Khaled N, Odhiambo J, Pearce N, et al. Prevalence of symptoms of asthma, rhinitis and eczema in 13- to 14-year-old children in Africa: The International Study of Asthma and Allergies in

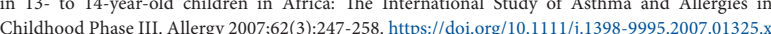

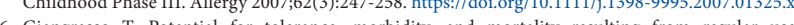
Giangrasso T. Potential for tolerance, morbidity, and mortality resulting from regular use of beta 2-adrenergic agonists in asthma. South Med J 1997;90(2):17317-17319. https://doi.

7. Suissa S, Ernst P, Boivin JF, et al. A cohort analysis of excess mortality in asthma and the use of inhaled beta-agonists. Am J Respir Crit Care Med 1994;149(3):604-610. https://doi.org/10.1164/ ajrccm.149.3.8118625

8. Pauwels RA, Pedersen S, Busse WW, et al., START Investigators Group. Early intervention with budesonide in mild persistent asthma: A randomised, double-blind trial. Lancet 2003;361(9363):1071-1076. https://doi.org/10.1016/S0140-6736(03)12891-7

9. Reddel HK, Busse WW, Pedersen S, et al. Should recommendations about starting inhaled corticosteroid treatment for mild asthma be based on symptom frequency: A post-hoc efficacy analysis of the START study. Lancet 2017:389(10065):157-166. https//toi A post 10.1016/S0140analysis of the STAR

10. Global Initiative for Asthma. Global strategy for asthma management and prevention. 2019. https://ginasthma.org/wp-content/uploads/2019/06/GINA-2019-main-report-June-2019-wms.pdf (accessed 20 March 2020)

11. Asthma Control Test. https://www.asthmacontroltest.com/en-za/quiz/children-quiz/ (accessed 25 January 2021).

12. Masekela R, Gray C, Green RJ, et al., on behalf of the South African Childhood Asthma Working Group. The increasing burden of asthma in South African children: A call to action. S Afr Med J 2018;108(7):537-539. https://doi.org/10.7196/SAMJ.2018.v10817.13162

13. Pentz A, Els C, Coetzee O, Green RJ. An idea children's chest and allergy clinic. Curr Allergy Clin Immunol 2014;27(1):9-13.

14. Green RJ, Sinclair W. General approach to and summary of the guideline for the management of atopic dermatitis. S Afr Med J 2014;104(10):705. https://doi.org/10.7196/samj.8865

15. Todd G, Manira A, Sinclair W, Levin M, Green RJ. Non-pharmacological treatment modalities for atopic dermatitis in South Africa. S Afr Med J 2014:104(10):713 https://doi.org/10.7196/SAMJ.8860

16. Green RJ, Hockman M, Friedman R, et al., on behalf of the South African Allergic Rhinitis Working Group (SAARWG). Chronic rhinitis in South Africa - more than just allergy! S Afr Med J 2020;110(7):594-598. https://doi.org/10.7196/SAMJ.2020.v110i7.14553

17. Global Initiative for Asthma. COVID-19: GINA answers to frequently asked questions on asthma management. https://ginasthma.org/covid-19-gina-answers-to-frequently-asked-questions-on-asthmamanagement/ (accessed 25 January 2021)

18. Manjra AI, van Niekerk A, White DA, et al. Summary of childhood asthma guidelines, 2021: A consensus document of the South African Asthma Childhood Working Group, a sub-committee of the Allergy Society of South Africa. S Afr Med J 2021:111(5):395-399. https://doi.org/10.7196/ SAMJ.2021.v111i5.15703

19. Green RJ. Viral infections, COVID-19 and asthma: Preventing viral exacerbations of asthma. S Afr Med J 2021;111(5):400-401. https://doi.org/10.7196/SAMJ.2021.v11115.15707

S Afr Med J 2021;111(5):393-394. https://doi.org/10.7196/SAMJ.2021.v111i5.15702 